\title{
Study of Routing Overhead and Its Protocols
}

\author{
Kiran Rampurkar, Nikhil Lavande, Santosh Shilgire and Sayali N. Mane
}

\begin{abstract}
The mobile Ad Hoc Network which is popularly known as MANET is basically one of world famous wireless mobile network, containing multiple nodes without any central hub or administration connecting between them. As nodes are mobile and dynamic topology, routing becomes important aspect in MANET. Routing mainly concentrates on searching the propagation link between source and destination. For node mobility in MANETs, it is quite simple link breakages or moving, hence routing becomes the crucial in Mobile Ad Hoc Networks. To find such proper link, various routing protocols are available. Mainly there are three popular routing protocols Reactive, Proactive and Hybrid also consider for analysis purpose. There are many performance metrics to check for the pros and cons of each routing protocols like packet delivery ratio (PDR), delay, routing overhead, throughput etc. are also discussed here.
\end{abstract}

\section{Keywords}

Ad Hoc Networks, Network protocol, Packet delivery, performance analysis of routing protocol, Routing protocols analysis, Wireless networking.

\section{INTRODUCTION}

The MANET is a unique kind of wireless portable system in which transportable/moving host can converse lacking any condition of recognized communications and be able to be used for a lot of submission [1]. MANETs are set of mobile nodes those are move freely. These freely moving nodes without any fix structure are able to dynamically self organized. Lot of direction-finding procedure, such as Ad hoc DSR or Dynamic Source Routing and Distance Vector Routing (AODV) are useful for MANETs [2].

The DSR or Dynamic Source Routing protocol is basically an easy, straightforward, less complex also a wellorganized direction-finding procedure planned specially for utilize in wireless communication with multi-hop methodology is a informal system of portable nodes [3]. DSR permit the system to be totally self-organizing, devoid of the requirement for any obtainable system communications or management.

AODV has ability to discover the path by using unicast as well as multicast techniques. Generally AODV is based on

Authors Details:

*Kiran Rampurkar

e-mail: kiranrampurkar19@gmail.com

Nikhil Lavande

email:nikhillavande.108@gmail.com

Santosh Shilgire

email: sshilgire@gmail.com

Sayali N. Mane

email: sayalimane@rediffmail.com

Dept. of ECE, D Y Patil College of Engineering, Akurdi, India

Subject Category: Communication

Sub Category: Mobile Ad Hoc Network.

Editor-in-Chief: Dr. Sahadev Roy insist methodology, significance which construct direct connecting nodal points only as wanted by basis nodes [4]. It preserves those direct and essential by the basis. In the following section we discussed different performance analysis of the routing overhead protocol.

\section{ROUTING OVERHEAD TECHNIQUES}

In MANET, breakage of general and frequent links occurs due to the mobility of nodes and frequent route searching. This type of overhead route discovery can't be tolerated. But as in MANET nodes are mobile selected path for packet transmission might get interrupted [5]. This leads to rerouting of the path every time a node moves from its position. The process is explained in the following example:

Consider we have to transmit a packet from node $\mathrm{A}$ to node L. And the shortest possible path is given by A-B-C-G-J-D-ML. When transmission has been started packet is transmit from the source node A to the nearest node $\mathrm{B}$. When packet reaches node $\mathrm{C}$ it is expected that it will send packet to the next node G.

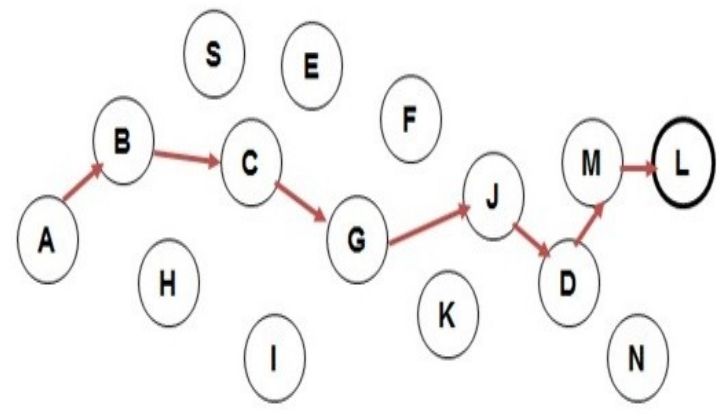

Fig.1. Original path $A-B-C-G-J-D-M-L$.

But as nodes are mobile consider $\mathrm{G}$ has travelled some distance then $\mathrm{G}$ is not within the reachh of $\mathrm{C}$ as shown in following Fig. 2. Hence path is disconnected and packet is at node C. Now path needs to be rerouted so that packet reaches 
node L. Node $\mathrm{C}$ requests node $\mathrm{E}$ and Node I for transmission. Consider Node $\mathrm{E}$ has replied with positive acknowledgment to request from Node $\mathrm{C}$. Then Transmission will take place in route as shown Fig. 3.

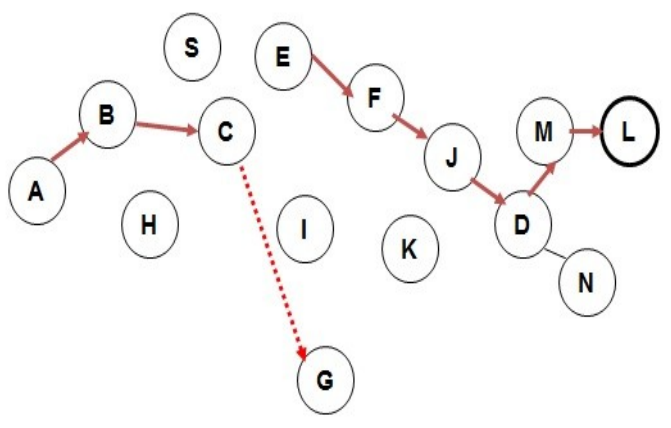

Fig.2. Breakage due to movement of node $G$

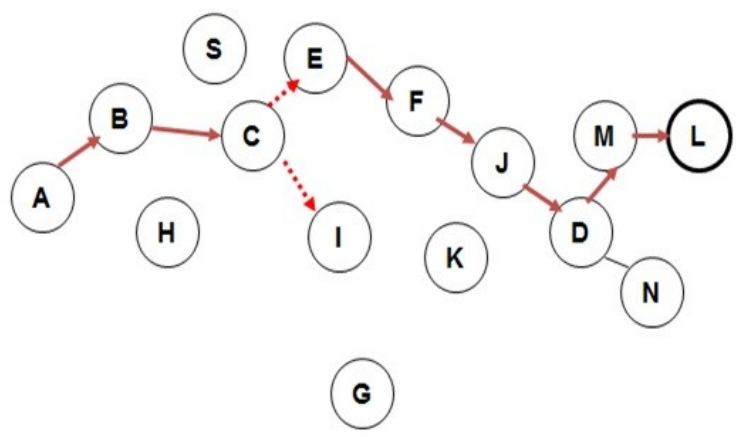

Fig.3. New route discovery $A-B-C-G-J-D-M-L$.

\section{Routing Protocols}

\section{A. Proactive routing protocols}

Here the entire nodes constantly look for direction-finding in order through in a system, consequently that at what time a direct is essential, the way is previously recognized. If one bump needs to post some data to one more knot, pathway is recognized, consequently, latency is little. Though, a group of nodule faction then the price of preserve all topology.

\section{B. Reactive Routing protocols}

For finding the link from any source to destination a question answer type algorithm is known as reactive. Hence, the latency is high and any type of control messages are not essential.

\section{Hybrid routing protocols}

These procedures include the qualities of practical in addition to thoughtless direction-finding protocols. A cross direction-finding procedures have to make use of a combination of together practical and thoughtless approach. Therefore, in the new years, some cross direction-finding practice are planned like SHARP, ZHLS, ZRP and NAMP etc.

\section{DSR (Dynamic Source Routing):}

The dynamic source routing shortly known as DSR protocol is a resting on steering procedure founded on basis direction-finding. In this source-routing method, a correspondent (sender) decides the accurate progression of the nodes throughout broadcast a package. The record of the intermediary nodes for steering is explicitly enclosed in the package's header. In this system each portable node in the setup requires to keep a direct supply.

Route maintenances and root discovery are basically the two main consideration of the DSR protocol. When any host try to transmit data packet to other host, it verify its route cache for detecting a suitable route to propagate the packet the at the desired destination [6]. If the suitable root not discovered the source node again take initiative to root discovery process again.

The source node is broadcast packet which contains route request. Within its wireless transmission range all neighbour nodes received that packet. This packet mainly contains the host target address, the source address in the particular arrangement, a route recorder with a unique identifier [7]. The host node may receive a reply packet generally contain a list of all available network link nodes. All early hops sequence, initiates the route record like a list containing self information and subsequently neighbour node information appends. There are two possible processes to complete this task. The hop-byhop acknowledgment at the data link layer configure as an early and re transmission of lost or damaged corrupt packets.

\section{E. AODV Routing}

The improve version of DSDV is AODV tough it is reactive in nature. The number of broadcasts depends on demand. It transmit a RREQ or route request generate if any source try to send any packet to a desired destination like a relay system. For forwarding the RREQ, intermediate nodes may keep record the address of the receiver in their route tables first copy is received. This table may used for establishing a reverse path [8]. If any intermediate node changes the same information passed by using relay process and reach the destination. In DSDV, each ad hoc nodal value monotonically increase by using a general sequence number counter [9]. This process increases the bandwidth by data traffic control mechanism through the responsive changes in topology and unnecessary loop.

\section{F. TORA and DSDV}

Temporally Ordered Routing Protocol i.e. TORA is circulated extremely adaptive routing protocol considered to work in an active multichip set-up. It uses an uninformed elevation restriction to decide the route of relationship involving any two nodes for a specified goal [10]. Subsequently several direction regularly subsist for a given purpose but not any of them are automatically the express transmit. To begin the route, the host node rebroadcasted the same query packet and based on the acknowledgement it decide new route search or search for new route. The

\section{RESUlt ANALYSIS}

From the referred papers we conclude the following results considering the various scenarios, we can get difference in parameters for each routing protocols.

\section{A. Performance Metrics}

The performance metrics shown in Table 1, which may be consider evaluating the MANETs routing protocols as:

Average Delay: It may be consider as the average time taken to reach the destination from source, which associated with all kind of delays due to the buffering in transmission path 
discovery latency, due to interface in between the queue, delay due to repeat transmission in MAC, and transfer times.

Number of packets lost: The droop of data-packets generally in the network layer by routers for the buffer limitation or may be the buffering time go beyond the estimated time limit.

Problem Related to Routing Overhead: It may be consider as the quantity of routing packets sent for maintenance and also for route discovery.

Throughput: It may be consider as the ratio of packets which are received by the target receiver and the quantity of sent packet. This parameter should be high where

\section{B. Ratio of Routing and the Packet Delivery Ratio}

Following table shows how routing and the packet delivery ratio will change for DSR, AODV, TORA for (i) Low Mobility, Low Traffics and (ii) High Mobility and High Traffic.

If requirements of the system are less routing overhead and lesser packet delivery ratio(PDR) and system is having less mobility and low traffic, it is better to use DSR or AODV over TORA.

If requirements of the system are less routing overhead and lesser packet delivery ratio (PDR) and system is having High mobility and high traffic which most MANETs have, it is much better if we utilize the concept of DSR or TORA over AODV [11]. TORA generally used where PDR is essential.

\section{Average Pair to Pair Delay and Optimum path:}

Following table shows how average delay and optimum path will change for DSR, AODV, TORA for poor mobility and less traffics and high speed and large amount of traffic.

Table 1. Comparisons between DSR, AODV and TORA in different traffic condition

\begin{tabular}{|c|c|c|c|c|}
\hline \multirow{2}{*}{$\begin{array}{c}\text { Traffic } \\
\text { Condition }\end{array}$} & \multirow{2}{*}{ Property } & \multicolumn{3}{|c|}{ Protocol } \\
\hline & & DSR & AODV & TORA \\
\hline \multirow{4}{*}{$\begin{array}{c}\text { Low } \\
\text { Mobility } \\
\text { and Low } \\
\text { Traffic }\end{array}$} & $\begin{array}{c}\text { Routing } \\
\text { Overhead }\end{array}$ & Low & Low & Average \\
\hline & PDR & High & High & High \\
\hline & $\begin{array}{c}\text { Avg. E-E } \\
\text { Delay }\end{array}$ & Moderate & Moderate & Low \\
\hline & $\begin{array}{l}\text { Optimal } \\
\text { Path }\end{array}$ & Average & Very good & Good \\
\hline \multirow{4}{*}{$\begin{array}{c}\text { High } \\
\text { Mobility } \\
\text { and High } \\
\text { Traffic }\end{array}$} & $\begin{array}{c}\text { Routing } \\
\text { Overhead }\end{array}$ & Average & Very High & High \\
\hline & PDR & Average & Average & Low \\
\hline & $\begin{array}{c}\text { Avg. E-E } \\
\text { Delay }\end{array}$ & Average & Average & More \\
\hline & $\begin{array}{l}\text { Optimal } \\
\text { Path }\end{array}$ & Less & Moderate & Moderate \\
\hline
\end{tabular}

If requirements of the system are less Average End to End delay and optimal path and system has low mobility and less traffic then AODV or TORA can be used over DSR. As AODV can be used where getting optimum path is primary requirement of the system while TORA can be used where pair to pair average propagation time is primary concern. If the desired requirements of the system are lessdelay is minimum and optimal path and system has high mobility and high traffic. Then DSR routing protocol should be preferred over
AODV and TORA. There are some benefits and limitations in the DSR procedures. There is no requiring to maintain mapreading chart therefore a given information package as the whole way is controlled in the packets header which is one of the important benefits of DSR protocol. On the other hand there is not scalable to big system and still want considerably extra dispensation funds than the majority of the other protocols which is the main restriction of DSR protocol.

\section{Conclusions}

To minimizing routing overhead is main aim of the system following protocols should be used. When numbers of nodes are less AODV has lesser routing overhead as compared to DSDV. But as the number of nodes start to increase overhead in AODV increases proportionally as compared to overhead in DSDV. Because the AODV is generally a demand based routing protocol routing overhead increase when the node element increases. TORA has worst performance for routing overhead in comparison with other whereas DSR has best performance for routing overhead problem.

\section{REFERENCES}

[1] M.V. Khiavi, S. Jamali and S.J. Gudakahriz, "Performance Comparison Of AODV, DSDV, DSR and TORA Routing Protocols in MANETs",International Research Journal of applied And Basic Sciences vol. 3, no. 7, pp. 1429-1436, 2012.

[2] K. Prabu and A. Subramani, "Performance Comparison of Routing Protocols in MANET",International Journal of Advanced Research in Computer Science and Software Engineering, vol. 2, no. 9, 2012.

[3] M.K. Gulati and K. Kumar "Performance Comparison of Mobile Ad Hoc Network Routing Protocols,"

International journal of Computer Networks \& Communications vol. 2, no. 2, pp. 127-142, 2014. https://doi.org/10.5121/ijenc.2014.6211

[4] K. Pandey and A. Swaroop, "A Comprehensive Performance Analysis of Proactive, Reactive and Hybrid MANETs Routing Protocols," International Journal of Computer Science Issues, vol. 8, no. 6, pp. 432-411, 2011.

[5] S.S. Dhenakaran and A. Parvathavarthini, "An Overview of Routing Protocols in Mobile Ad-Hoc Network", International Journal of Advanced Research in Computer Science and Software Engineering, vol. 3, no. 2, pp. 251259, 2013.

[6] T.R. Devi, "Implementation of Dynamic Source Routing (DSR) In Mobile Ad Hoc Network Manet" , International Journal of Research in Engineering and Technology, vol. 2, no. 11, pp. 339-345, 2013. https://doi.org/10.15623/ijret.2013.0211053

[7] Z. Wang and X. Zhang "Improvement of AODV Routing Protocol in Mobile Ad Hoc network," Journal of Computer Applications, Vol. 30, no. 2, pp. 333-336,

2010. https://doi.org/10.3724/sp.j.1087.2010.00333

[8] L. Raja and S. S. Baboo, "Comparative study of reactive routing protocol (AODV, DSR, ABR and TORA) in MANET," International Journal of Engineering and Computer Science, vol. 2, no. 3, pp. 707-718, 2013.

Kiran Rampurkar, Nikhil Lavande, Santosh Shilgire and Sayali N. Mane, "Study of Routing Overhead and Its Protocols," International Journal of Advanced Engineering and Management, vol. 2, no. 2, pp. 52-55, 2017. https://ijoaem.org/0020205-2/ 
[9] A. Bhangu, N. Kaur, "An Efficient OLSR and TORA Routing Protocols for MANETs", International Journal of Advanced Research in Computer Science and Software Engineering, vol. 5, no. 7, 2015.

[10] R. Sharma, R. Sindhu, "Study of TORA FOR Mobile Adhoc Network," International Journal of Computer Science and Information Technologies, vol. 5, no. 4, pp. 49024905, 2014.

[11] A. Makkar, B. Bhushan and S. Taneja, " Behavioral Study of Manet Routing Protocols," International Journal of Innovation, Management and Technology, vol. 2, no. 3, pp. 210-216, 2011. 